\title{
Mach Number Effects on Turbine Blade Transition Length Prediction
}

R.J. Boyle and F.F. Simon

Lewis Research Center, Cleveland, Ohio

Prepared for the

Turbo Expo '98

sponsored by the American Society of Mechanical Engineers

Stockholm, Sweden, June 2-5, 1998

National Aeronautics and

Space Administration

Lewis Research Center 
Available from

NASA Center for Aerospace Information 7121 Standard Drive

Hanover, MD 21076

Price Code: A03
National Technical Information Service 5287 Port Royal Road Springfield, VA 22100 Price Code: A03 


\title{
MACH NUMBER EFFECTS ON TURBINE BLADE TRANSITION LENGTH PREDICTION
}

\author{
R. J. Boyle \\ NASA Lewis Research Center \\ Cleveland, $\mathrm{OH} 44135$ \\ F. F. Simon \\ NASA Lewis Research Center, (Ret.) \\ Cleveland, $\mathrm{OH} 44135$
}

\begin{abstract}
The effect of a Mach number correction on a model for predicting the length of transition was investigated. The transition length decreases as the turbulent spot production rate increases. Much of the data for predicting the spot production rate comes from low speed flow experiments. Recent data and analysis showed that the spot production rate is affected by Mach number. The degree of agreement between analysis and data for turbine blade heat transfer without film cooling is strongly dependent of accurately predicting the length of transition. Consequently, turbine blade heat transfer data sets were used to validate a transition length turbulence model. A method for modifying models for the length of transition to account for Mach number effects is presented. The modification was made to two transition length models. The modified models were incorporated into the two-dimensional Navier-Stokes code, RVCQ3D. Comparisons were made between predicted and measured midspan surface heat transfer for stator and rotor turbine blades. The results showed that accounting for Mach number effects significantly improved the agreement with the experimental data.
\end{abstract}

\section{Nomenclature}

$A^{+} \quad$ - Near wall damping coefficient

$C_{m}$ - Ratio of compressible-to-incompressible spot production rate

c - True chord

$c_{x}$ - Axial chord

$f$ - Frequency

$h$ - Heat transfer coefficient

$h_{R}$ - Normalizing heat transfer coefficient

$I$ - Incidence angler

$K$ - Acceleration parameter

$N$ - Nondimensional spot formation rate

$n$ - Spot formation rate

$R e$ - Reynolds number

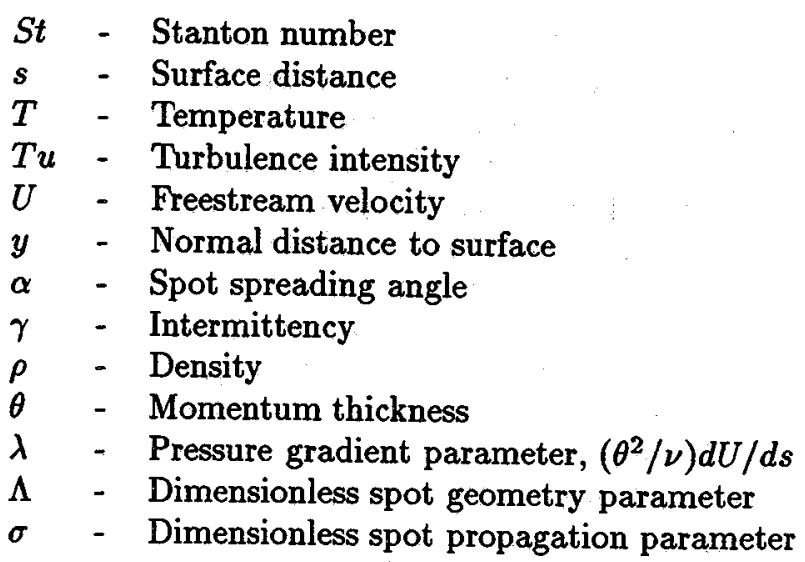

$\begin{array}{lll}\text { Subscripts } & \\ \text { d } & - & \text { Leading edge diameter } \\ \text { GAS } & - \text { Molecular } \\ \text { LAM } & - \text { Laminar } \\ \text { M } & - \text { Value as a function of Mach number } \\ \text { P } & - \text { Pressure surface } \\ \text { S } & - \text { Surface distance from stagnation point; } \\ & & \text { Suction surface } \\ \text { ST } & - \text { Start of transition } \\ \text { T } & - \text { Total surface distance } \\ \text { TURB } & - \text { Turbulent } \\ \text { IN } & - \text { Gas inlet } \\ 0 & - \text { Start of transition } \\ 0.1 & - \text { Value at incompressible condition } \\ 2 & - \text { Blade row exit } \\ 99 & - & 99 \% \text { Intermittency }\end{array}$

\section{INTRODUCTION}

The accuracy of predictions for turbine blade aerodynamics and heat transfer is affected by the accuracy in predicting the region of transitioning flows. The locations on the blade where transition begins and ends can affect the aerodynamic performance. In applications where turbine blade film cooling is absent, knowledge of where transition begins and ends is important in 
predicting surface heat transfer. As discussed by Mayle (1991), there is an extensive amount of experimental data showing that the start and length of transition are functions of Reynolds number, turbulence intensity, and pressure gradient, in addition to any periodic disturbances which may be present.

Much of the recent theoretical analysis for the length of transition utilizes the spot production concept of Emmons (1951) for intermittency. Narasimha (1957) proposed that the intermittency follows an exponential behavior, with the exponential term being proportional to the square of the distance from the start of transition. The model proposed by Chen and Thyson (1971) accounted for variable freestream velocity on the length of transition by an integral relationship in the exponential term. Two different approaches have been used to account for the effects of turbulence intensity and pressure gradient on the length of transition. Simon (1995), Gostelow et al. (1994), and Frazer et al. (1994) accounted for these effects by assuming that the flow conditions at transition onset were the dominant influences. Solomon et al. (1995) extended the approach of Chen and Thyson (1971) to account for free stream flow variations on the length of transition.

Most of the experimental data used to develop correlations for the transition length were obtained at incompressible flow conditions. There is only a limited amount of data which show the effect of Mach number on transition for the transonic flow regime. Dey and Narasimha (1985) proposed a variation in the spot formation rate with Mach number. Their variation showed no change in the spot formation rate until a Mach number of two, followed by a rapid decrease in the Mach two-to-four range. Recent data by Clark et al. (1994) showed that the effect of Mach number on turbulent spot parameters was significant at substantially lower Mach numbers. Mack (1969) showed the effect of Mach number on the frequency of the Tollmien-Schlichting waves, which in turn affects the spot formation rate.

The transition spot data of Clark (1993), and the frequency results of Mack (1969) were used to derive modifications to account for the effect of Mach number on the length of transition. The modifications were incorporated into the models proposed by Simon (1995), and Solomon et al. (1995). These models were then implemented in a Navier-Stokes code. The code used, (RVCQ3D), has been documented by Chima (1987), and Chima and Yokota (1988). Comparisons with experimental turbomachinery data showed that incorporating Mach number effects into the transition length model improved the agreement with experimental data. Accurate transition predictions are important whether or not surface heat transfer is present. Turbine blade heat transfer data can dramatically show transition behavior, and data are available at high freestream Mach numbers. Therefore, turbine blade heat transfer data was chosen to illustrate the importance of including a Mach number effect on the length of transition.

The work presented herein consists of a discussion of how Mach number effects were incorporated into the transition length model. Comparisons are then shown for a variety of turbine conditions to show that incorporating a Mach number effect significantly improves the degree of improvement with the experimental data. Comparisons are made with data for both stator and rotor geometries for a range of turbulence intensities and Reynolds numbers. This is done to demonstrate that the Mach number effect is a general one, which leads to an overall improvement, and not just for a specific test case. Results are shown for two different transition length models in order to demonstrate that the results are not a function of a particular transition length model.

\section{DESCRIPTION of ANALYSIS}

In the transition region the effective eddy viscosity, $\mu_{\mathrm{EFF}}$, is given by:

$$
\mu_{\mathrm{EFF}}=\mu_{\mathrm{LAM}}+\gamma \mu_{\mathrm{TURB}}
$$

Different approaches have been used to determine the value of intermittency, $\gamma$. Two recent approaches to calculating the value of $\gamma$ are those of Simon (1995), and Solomon et al. (1995). In both methods the intermittency, $\gamma$, is a function of the pressure gradient $\lambda$. In the model of Solomon et al. the intermittency is also a function of the turbulence intensity, $T u$. Simon's (1995) method utilizes an analytically developed value for the spot production rate, while the method of Solomon et al. (1995) utilizes a experimentally derived correlation for the spot production rate.

Simon's Model. In Simon's (1995) model $\gamma$ is based on the intermittency path equation derived by Narasimha (1957):

$$
\gamma_{\text {Simon }}=1.0-\exp \left[-n \sigma\left(R e_{\mathrm{S}}-R e_{\mathrm{S}-\mathrm{ST}}\right)^{2}\right]
$$

The parameters in this equation are given by:

$$
n \sigma=N / R e_{\theta_{S T}}^{3}
$$

Simon (1995) developed an analytic value for the nondimensional spot production rate, $N$. 


$$
N=8.1 \times 10^{-4}\left(\frac{\Lambda \tan \alpha}{\beta}\right)_{\mathrm{ST}}^{2}
$$

Simon and Ashpis (1996) showed results using values for $\Lambda, \alpha$, and $\beta$ determined from the data of Gostelow et al. (1995). The dimensionless spot parameter, $\Lambda$, is the ratio of the spot area to the square of the spot half width. $\Lambda$ was determined from the zero pressure gradient data to be 2.88. $\alpha$ and $\beta$ at the start of transition were taken as functions of pressure gradient.

$$
\begin{gathered}
\alpha_{\mathrm{ST}}=4.0+\left(\frac{22.14}{0.79+2.72 e^{47.63 \lambda_{S T}}}\right) \\
\beta_{\mathrm{ST}}=0.71+1.35 / \lambda_{\mathrm{ST}}
\end{gathered}
$$

Solomon, Walker, Gostelow,(SWG), Model. In the model developed by Solomon Walker and Gostelow (1995)

$$
\gamma_{\mathrm{SWG}}=1.0-\exp \left[n \int_{s_{S T}}^{s} \frac{\sigma}{U \tan \alpha} d s \int_{s_{\mathrm{ST}}}^{s} \tan \alpha d s\right]
$$

In this equation $n$ is determined by the values at the start of transition; while $\sigma, \alpha$, and $U$ are functions of the local conditions throughout the length of transition. The parameters in the above equation are:

$$
n=\frac{N_{\mathrm{ST}} \nu}{\sigma_{\mathrm{ST}} \theta_{\mathrm{ST}}^{3}}
$$

For favorable pressure gradients, $\lambda_{\mathrm{ST}}>0.0$, and

$$
N_{\mathrm{ST}}=8.6 \times 10^{-4} \exp \left(-10 \sqrt{\lambda_{\mathrm{ST}}}-0.564 \ln T u\right)
$$

Otherwise,

$$
N_{\mathrm{ST}}=8.6 \times 10^{-4} \exp \left(2.134 \lambda_{\mathrm{ST}} \ln T u-59.23 \lambda_{\mathrm{ST}}-0.564 \ln T u\right)
$$

The variables calculated throughout the transition length are given by:

$$
\begin{gathered}
\alpha=4.0+\left(\frac{22.14}{0.79+2.72 e^{47.63 \lambda}}\right) \\
\sigma=0.03+\left(\frac{0.37}{0.48+3.0 e^{59.2 \lambda}}\right)
\end{gathered}
$$

The primary differences between the transition length model of Simon and the SWG model of Solomon et al. (1995) are that Simon's model is based exclusively on the conditions at the start of transition, and that these conditions are not a function of the local turbulence intensity.

There is no explicit Mach number effect for the correlations used in either transition length model. The measurements which provided the data for the correlations were done at low Mach numbers where the flow is incompressible. Clark et al. (1994) reported experimental data showing that the freestream Mach number affects the spot spreading angle.

Mach Number Effects. Narasimha (1985) postulated that the transition process is likely to be the same for subsonic and supersonic flows.. The effect of increasing Mach number is to decrease the longitudinal growth rate of turbulent spots. Owen and Horstman (1972) showed intermittency data at hypersonic Mach numbers which agreed with the intermittency distribution developed by Narasimha (1957) for incompressible flows. Dey and Narasimha (1985), proposed a variation in the nondimensional spot formation rate, $N$, with Mach number. This variation showed little change up to a Mach number of two. For $2<M<4, N$ decreases rapidly. Recent data of Clark (1993), however, showed that there was a significant decrease in the spot spreading angle even for Mach numbers less than one. Simon (1995) utilized the method used by Walker (1989) and by McCormick (1968), regarding the frequency of spot formation. The turbulent spots are assumed to appear at the frequency of the Tollmein-Schlichting instability wave with the maximum amplification rate. The analysis of Mack (1969) showed that the frequency of the Tollmein-Schlichting instability wave with the maximum amplification rate decreased with Mach number up to sonic conditions. Simon (1995) showed that the spot formation rate, $N$, and thus $n$, is proportional to the square of the product of the spot formation frequency, $f$ and the tangent of the spot spreading angle, $\alpha$.

$$
n \propto(f \tan \alpha)^{2}
$$

The spot production rate at a given Mach number, $N_{\mathrm{M}}$, can be related to the incompressible spot production rate, $N_{0.1}$, by:

$$
C_{m}=\frac{n_{\mathrm{M}}}{n_{0.1}}=\frac{N_{\mathrm{M}}}{N_{0.1}}=\left(\frac{\tan \alpha_{\mathrm{M}} f_{\mathrm{M}}}{\tan \alpha_{0.1} f_{0.1}}\right)^{2}
$$

The turbulent spot spreading angle data of Clark (1993), and the Tollmein-Schlichting wave frequency analysis of Mack (1969) were used to determine the effect of Mach number on the spot formation rate. Figure 1 graphically presents the relationship for the effect of 


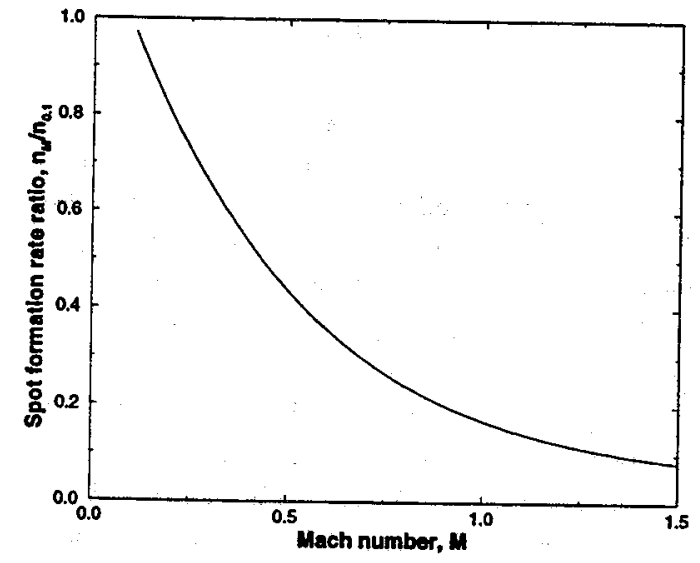

Fig 1 Effect of Mach number on spot formation rate.

Mach number on spot formation rate. The change in the spot production rate can be viewed as effectively increasing the length of transition by $\sqrt{n_{\mathrm{M}} / n_{0.1}}$

In summary, the transition length model of Simon including the effect of Mach number is:

$$
\gamma_{\mathrm{Simon}}=1.0-\exp \left[-n_{0.1}\left(\frac{n_{\mathrm{M}}}{n_{0.1}}\right) \sigma\left(R e_{\mathrm{S}}-R e_{\mathrm{S}-\mathrm{ST}}\right)^{2}\right]
$$

The Solomon, Walker Gostelow(SWG) model corrected for Mach number effects is:

$\gamma_{\mathrm{SWG}}=1.0-\exp \left[-n_{0.1}\left(\frac{n_{\mathrm{M}}}{n_{0.1}}\right) \int_{s \mathrm{ST}}^{s} \frac{\sigma}{U \tan \alpha} d s \int_{s_{S T}}^{s} \tan \alpha d s\right]$

In each model $n_{0.1}$ is calculated based on the pressure gradient, $\lambda$,and, for the SWG model, the turbulence intensity, $T u$.

The start of transition was specified using Mayle's (1991) method. The momentum thickness Reynolds number at the start of transition is given by

$$
R e_{\theta-\mathrm{ST}}=400 T u^{-5 / 7}
$$

The local turbulence intensity, $T u$, was determined using an algebraic relationship. To determine the local turbulence from a one or two equation turbulence model would require knowledge of the inlet length scale. For the cases examined, the inlet length scale was generally not available. The local turbulence intensity was calculated as:

$$
T u=T u_{\mathrm{IN}} U_{\mathrm{IN}} / U_{\mathrm{S}}
$$

The local freestream velocity, $U_{\mathrm{S}}$, was calculated from the local pressure ratio. Mayle (1991) recommended that a lower limit of $3 \%$ should be used for $T u$ when calculating $R e_{\theta}$ at the start of transition.
The transition models were incorporated into a quasi-3d Navier-Stokes analysis, (RVCQ3D). This code has been documented by Chima (1987), and by Chima and Yokota (1988). C-type grids were generated using the method of Arnone et al (1992). In this approach, the near-wall grid is embedded within a coarser grid obtained using the method of Sorenson (1980). For this work dense grids were used. A typical grid was $321 \times 51$. This was done to achieve high resolution within the transition region. The choice of grid parameters, such as near-wall spacing and stretching ratios was determined using the results presented by Boyle (1991) and by Boyle and Ameri(1997). Therefore, the conclusions drawn from this work would not be affected by the size of the grids used.

The Baldwin Lomax (1978) model was used for the turbulent eddy viscosity, $\mu_{\text {TURB }}$. This model was used for two reasons. First, it has been shown by Ameri and Arnone (1992), and by Chima (1996) that algebraic models of this type predict turbine blade surface heat transfer as accurately as two equation models. Second, an algebraic model, rather than a two equation model, allows a more straightforward demonstration of the effects of Mach number on the length of transition.

Because the freestream turbulence was high for many of the cases examined, the Smith and Kuethe (1966) model was incorporated to account for the effects of freestream turbulence on the laminar flow. The augmented laminar viscosity is:

$$
\mu_{\mathrm{LAM}}=\mu_{\mathrm{GAS}}+(1.0-\gamma) 0.164 \rho y T u U
$$

$y$ is the normal distance from the blade, and $\mu_{\mathrm{GAS}}$ is the molecular viscosity of the gas. Augmenting the laminar viscosity primarily affects the heat transfer in the leading edge region. The effect of the Smith and Kuethe (1966) model on the pretransition heat transfer will be discussed.

\section{DATA COMPARISONS}

In actual turbomachines most blade rows are subject to periodic flow field variations due to the presence of adjacent blade rows. The accuracy of prediction for the time averaged heat transfer would be affected by the accuracy in predicting the effects of the periodic disturbances. Since the objective of this work is to illustrate the importance of Mach number effects, comparisons are made for isolated blade row test cases. In these test cases the blades were not subject to periodic disturbances. This eliminated the necessity of accurately predicting the periodic disturbance effect. 
Table I. Stator cases examined

\begin{tabular}{|c|c|c|c|c|c|c|c|c|c|c|}
\hline \multicolumn{11}{|c|}{ Data - Arts et al.(1990) } \\
\hline & & & \multicolumn{4}{|c|}{ Suction } & \multicolumn{4}{|c|}{ Pressure } \\
\hline $\begin{array}{l}R e_{2} \\
\times 10^{-6}\end{array}$ & $\overline{M_{2}}$ & $\begin{array}{r}T u \\
\%\end{array}$ & $B_{S T} / B_{T}$ & $\lambda_{0}$ & $8_{99} / B_{T}$ & $\overline{\lambda_{99}}$ & BST $/ E T$ & $\bar{\lambda}_{0}$ & ${ }_{699} / B_{T}$ & $\overline{\lambda_{99}}$ \\
\hline 2. & 0.9 & 6.0 & 0.30 & 0.019 & 0.78 & -0.141 & 0.12 & 0.075 & 0.77 & 0.105 \\
\hline 2. & 1.1 & 6.0 & 0.30 & 0.025 & 0.97 & -1.816 & 0.12 & 0.078 & 0.79 & 0.111 \\
\hline 2. & 1.1 & 4.0 & 0.30 & 0.024 & 0.97 & -1.922 & 0.24 & 0.066 & $>1$ & $97 \%$ \\
\hline 1. & 0.8 & 6.0 & 0.36 & 0.053 & 0.77 & -0.083 & 0.13 & 0.078 & 0.76 & 0.102 \\
\hline 1. & 1.1 & 6.0 & 0.57 & 0.025 & $>1$ & $77 \%$ & 0.10 & 0.070 & 0.62 & 0.133 \\
\hline \multicolumn{11}{|c|}{ Data - Hylton et al.(1983) } \\
\hline & & & \multicolumn{4}{|c|}{ Suction } & \multicolumn{4}{|c|}{ Pressure } \\
\hline $\begin{array}{l}R e_{2} \\
\times 10^{-6}\end{array}$ & $M_{2}$ & $\begin{array}{c}T u \\
\%\end{array}$ & ${ }_{\mathrm{SST}} / \varepsilon_{\mathrm{T}}$ & $\lambda_{0}$ & $\delta_{p 9} / \delta_{T}$ & $\lambda_{99}$ & $\delta_{S T} / s_{T}$ & $\lambda_{0}$ & $s_{99} / s_{T}$ & $\overline{\lambda_{99}}$ \\
\hline 1.5 & 0.90 & 8.3 & 0.28 & -0.005 & 0.58 & -0.167 & 0.10 & 0.014 & 0.48 & 0.114 \\
\hline 2.5 & 1.06 & 8.3 & 0.28 & -0.009 & 0.58 & 0.097 & 0.09 & -0.005 & 0.25 & 0.126 \\
\hline
\end{tabular}

The test cases chosen were those that showed transition occurring over a significant fraction of the surface distance. The literature shows many cases where transition occurs over a very short distance near the leading edge or close to the trailing edge. These cases were not suitable test cases. Generally, moderate to high levels of turbulence intensity were required in the test cases. It is necessary to examine data from a variety of different sources, and under different conditions, in order to insure that that the proposed method of accounting for Mach number effects results in improved predictive capability. Comparisons with a variety of different cases also illustrates where improvements in the models are needed. Both stator and rotor geometry test cases were examined. The stator cases chosen were from Arts et al. (1990), and from Hylton et al. (1983). The rotor cases presented were those of Arts et al. (1997). These data show rotor surface heat transfer for a range of Mach numbers, Reynolds numbers, and rotor incidence angles.

\section{Stators}

Table I summarizes the test conditions for each of the cases presented. The Reynolds and Mach numbers, as well as the upstream turbulence intensity are shown for each case. Predicted values at the beginning and end of transition are also shown in the Table. These predictions are for the Solomon, Walker, Gostelow,SWG, model with the Mach number effect included. The surface distance at which transition starts, $\left(s_{\mathrm{ST}} / s_{T}\right)$, and the surface distance at which $\gamma=99 \%,\left(s_{99} / s_{T}\right)$ are shown. The total surface distance, $s_{T}$, is different for the suction and pressure surfaces. The values given for $\lambda$ are the predicted values at the beginning and end of transition. The predicted values for $s_{99} / s_{T}$ and $\lambda_{99}$ vary according to the transition length model used. The values shown in the table, therefore, are primarily useful for orientation purposes. Where the table entry is $>1$ transition was not complete at the end of the vane, and the corresponding percentage number is the $\gamma$ value at the trailing edge.

Data of Arts et al. (1990). Figure 2 shows a comparison of measured and predicted isentropic surface

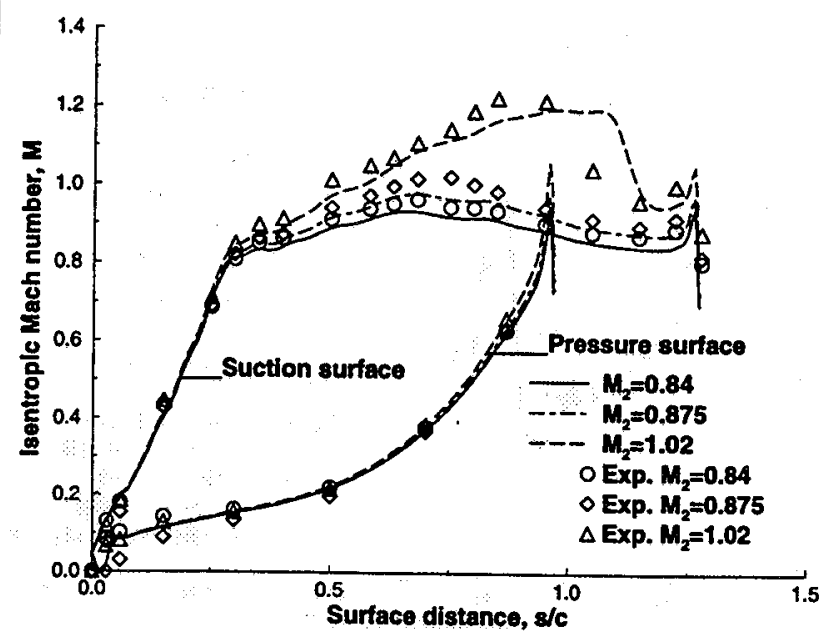

Fig. 2 isentropic surface Mach number. Data of Arts ot al.(1990)

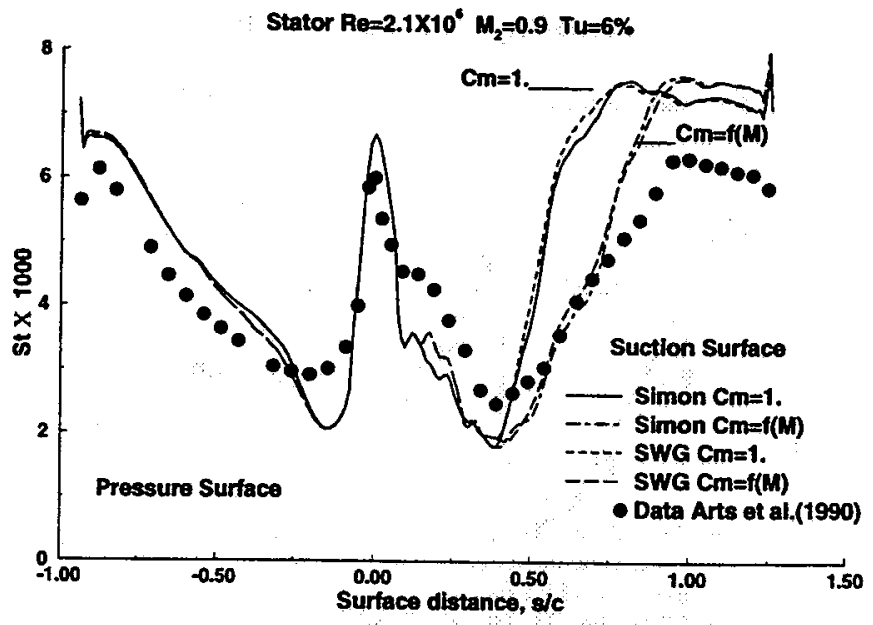

Fig 3 Effect of Mach number correction on predicted heat transfer.

Mach numbers for this geometry. Data were given at three different exit Mach numbers, $M_{2}$, which were somewhat different from the $M_{2}$ values used for the heat transfer tests. At the lowest Mach number, the suction surface Mach number peaks midway along the surface. At the highest Mach number the data show a peak Mach number at $80 \%$ of the surface distance, and the prediction shows the peak occurring somewhat later. Overall, the analysis agrees well with the data, and predicts most surface velocity gradients accurately.

Figure 3 compares heat transfer predictions with and without a Mach number correction with the experimental data. For this vane geometry, $s_{\mathrm{s}} / c=1.34$, and $s_{\mathrm{P}} / c=1.03$. The Stanton number, $S t$, is based on the vane exit conditions. These data are for an exit Reynolds number of $2 \times 10^{6}$, a $M_{2}=0.9$, and $T u=6 \%$. The predictions for the suction surface show that both Simon's model and the SWG model show improved agreement with data when the Mach number correction 


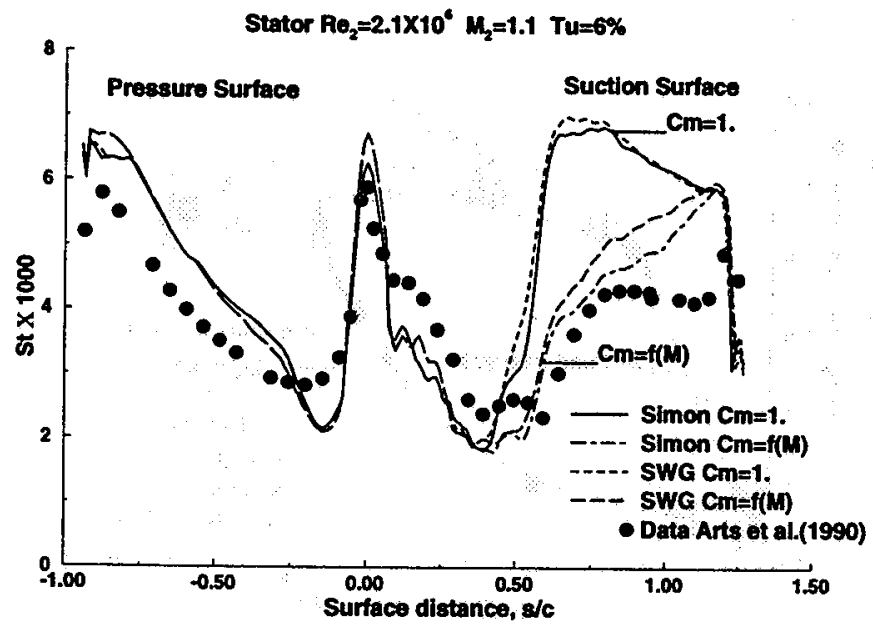

Fig. 4 Effect of Mach number correction on predicted heat transfer.

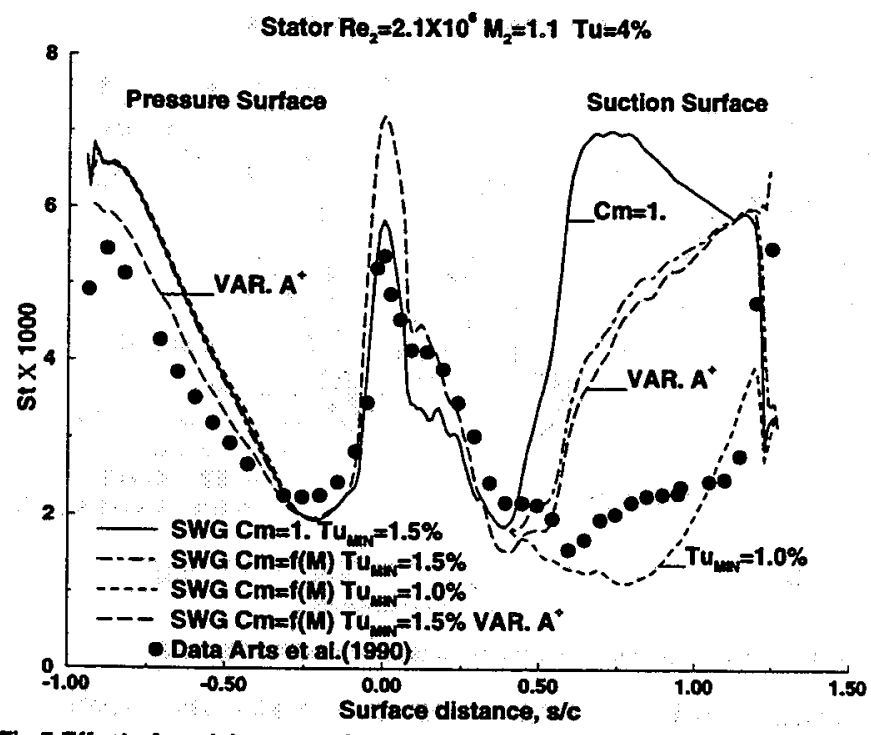

Fig 5 Effect of model assumptions on prodictod heat transfer.

is used. The predicted location for the start of transition on the pressure surface was close to the leading edge. Since this was a low Mach number region, the inclusion of a Mach number effect did not change the transition length prediction. The small differences on the pressure surface are due to the differences between the Simon and SWG turbulence models. Comparing the analysis and data shows that using the ratio of local-toinlet velocity to calculate the local turbulence intensity for the start of transition gives good agreement with the data.

Figure 4 shows comparisons for the same test conditions as in figure 3 , but at a higher exit Mach number, $M_{2}$, of 1.1. The Mach number at the start of transition is 0.92 . For both transition models including a Mach number correction in the transition length model signif-

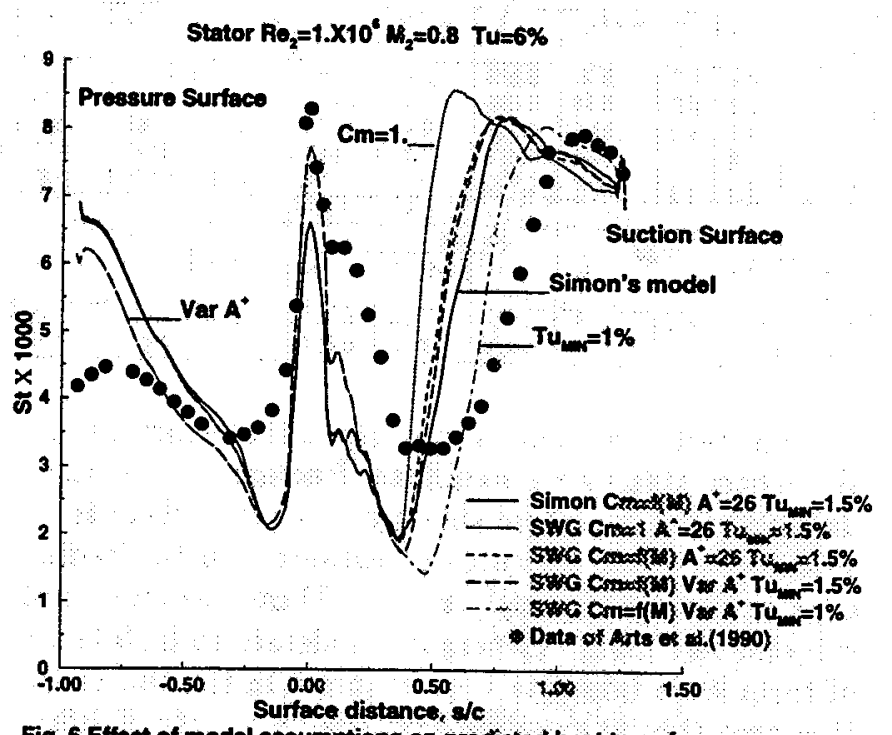

Fig. 6 Effoct of model assumptions on prodictod hoat transfor.

icantly improves the agreement for the suction surface. Along the aft portion of the suction surface, the analysis overpredicts the heat transfer. The implication of the results in this figure is that even though the Mach number correction substantially affects the length of transition, the effect may be underestimated. Mayle (1991), in a discussion of Sharma's (1987) results indicated that the intermittency used in the energy equation could be lower than that used in the momentum equations. If this approach had been taken in the analysis, the apparent transition length would be longer.

Figure 5 shows comparisons for a reduced upstream turbulence intensity of $4 \%$. The comparisons illustrate the importance of correctly predicting the start of transition. Because of the lower upstream turbulence intensity, the predicted turbulence intensity at the start of transition was very low. Mayle (1991) recommended a minimum intensity of $3 \%$ be used in calculating the start of transition. This value produced a very early transition. Comparisons with the data show that specifying a turbulence intensity of $1.5 \%$ produced an early suction surface transition, while an intensity of $1 \%$ gave a transition after the experimental results.

Figure 5 also illustrates the effect of a variable near wall damping coefficient, $A^{+}$, on predicted heat transfer. The variation of $A^{+}$with pressure gradient used is the same as that used by Crawford and Kays (1976) in the STAN5 boundary layer analysis program. Pressure surface transition occurs near the leading edge. The strong favorable pressure gradient results in an increased value for $A^{+}$. This in turn reduces the length scale in the near wall region, giving lower Stanton numbers. Paradoxicly, a variable $A^{+}$resulted in increased 


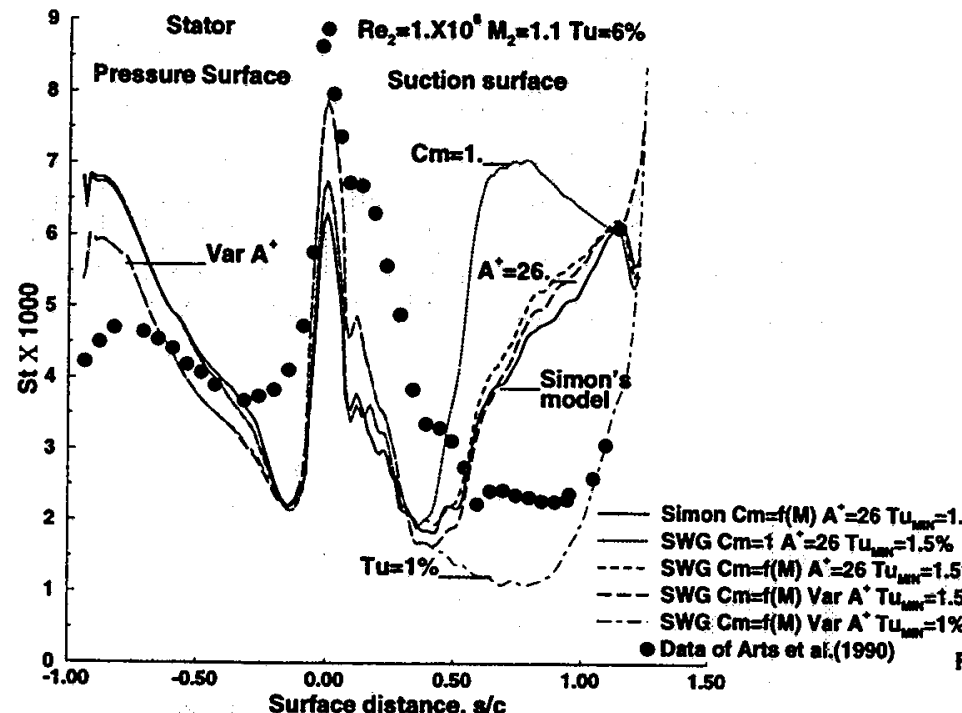

Fig 7 Effect of model assumptions on predicted heat transfor.

leading edge heat transfer. This unexpected behavior was caused by the manner in which the Smith and Kuethe (1996) leading edge augmentation model was incorporated into the analysis. The turbulence quantities were calculated everywhere, not just where $\gamma>0$. The Smith and Kuethe model was applied only in the inner region. However, the distance from the wall at which the turbulence model crossed over from the inner to outer regions was affected by $A^{+}$. When $A^{+}$was variable, the Smith and Kuethe model was applied over a greater distance from the wall than when $A^{+}=26$.

Next, comparisons are shown where the exit Reynolds number has been reduced in half. Figures 6 and 7 show results for $T u=6 \%$, and exit Mach numbers of 0.8 and 1.1. At this lower Reynolds number, the degree of agreement for the pressure surface heat transfer is significantly poorer. It is felt that the primary reason for the poorer agreement on the pressure surface is that the only mechanism for relaminarization is the variation in $\mathrm{A}^{+}$. From the data it appears that the increase in $A^{+}$at these test conditions is insufficient. Kays and Crawford (1980) state that a boundary layer will relaminarize at $K$ values around $1-3 \times 10^{-6}$. Since $\lambda=K R e_{\theta}^{2}$, if the pressure gradient is high enough, and transition occurs at a low enough $R e_{\theta}$, the boundary layer is likely to relaminarize. At high turbulence levels, transition begins at low $R e_{\theta}$. The values of $\lambda$, and $R e_{\theta}$ were calculated throughout the pressure surface transition region. The resulting $K$ values were greater than the $K$ value for relaminarization using the Kays and Crawford criteria.

On the suction surface the choice of transition start is the most influential factor in the heat transfer. As the

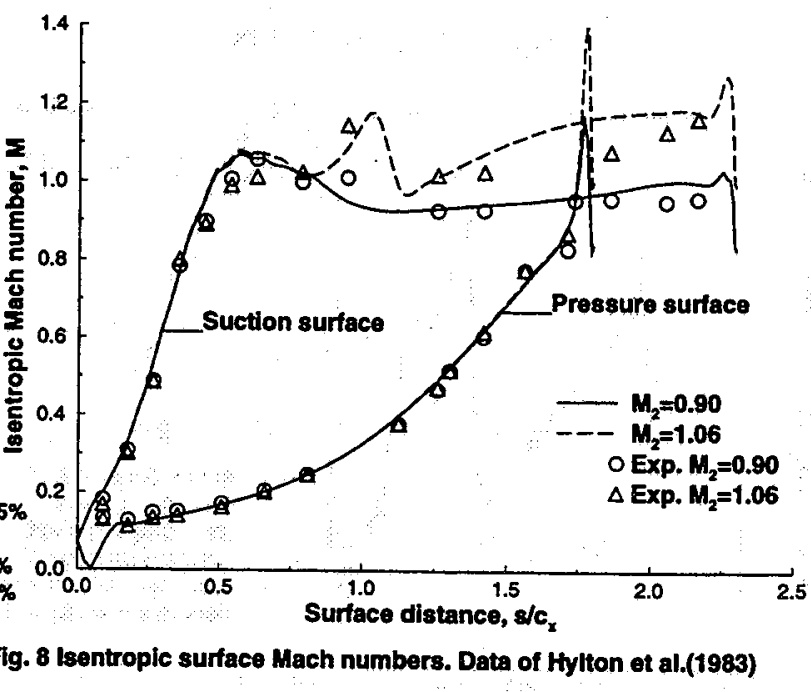

minimum turbulence intensity is lowered, the analysis gives better agreement with the data for the transition region. However, prîor to transition, and in the early part of transition, the predicted heat transfer signifcantly underpredicts the surface heat transfer.

Consistent with the results at the higher Reynolds number, the best agreement for the suction surface heat transfer occurs when the local turbulence intensity is close to $1 \%$. The overall conclusion from the comparisons regarding the start of transition is that the local turbulence intensity at transition start should not be specified. Rather, it should be calculated from an appropriate model, and not have a preset lower limit.

C3X data of Hylton et al. (1983). The predicted and experimental isentropic surface Mach numbers for test cases $4321,\left(M_{2}=0.90\right)$, and $5521,\left(M_{2}=1.06\right)$, are shown in figure 8. For the lower exit Mach number the peak suction surface Mach number is near $20 \%$ of the surface distance. The higher Mach number case has the peak close to $40 \%$ of the surface distance, after which there is rapid diffusion. From Table I it can be seen that transition is expected to start near $30 \%$ suction surface distance. If transition starts after the peak in suction surface velocity, the transition length is expected to be short because of the adverse pressure gradient. There is good agreement between the analysis and the data, except for the last third of the suction surface at the higher Mach number.

Figures 9 and 10 show comparisons between predicted and experimental heat transfer for cases 4321 and 5521. The actual heat transfer coefficient, $h$, was normalized by a reference value, $h_{R}$ of $1135 \mathrm{~W} / \mathrm{m}^{2} / K$, as was done by Hylton et al. The cases have the same inlet $T u,(8.3 \%)$, but differ in exit Reynolds and Mach numbers. In figure 9 the effect of including a Mach num- 


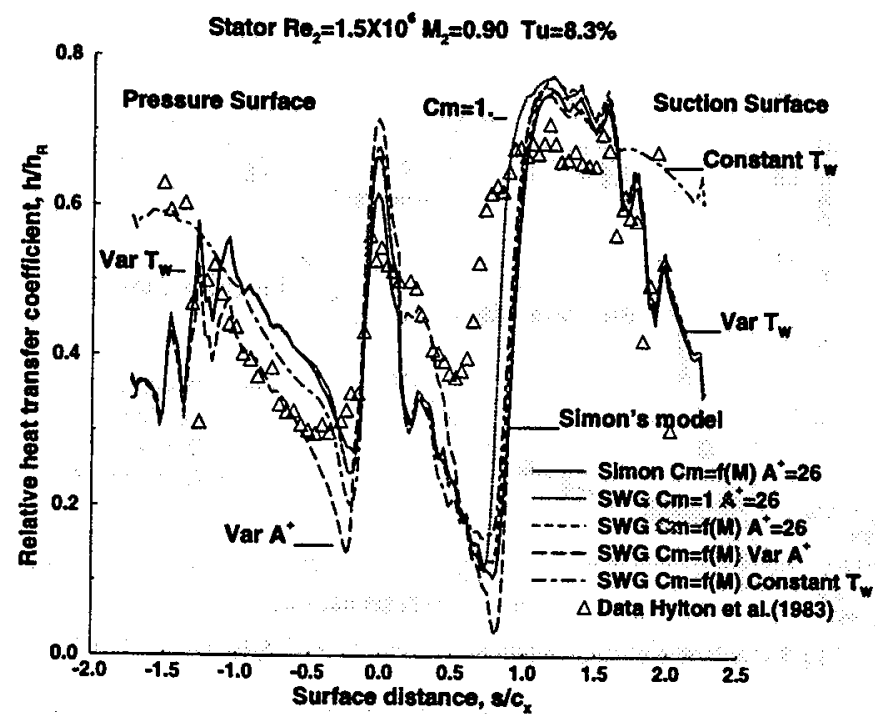

Fig. 9 Effect of modil assumptions on predicted heat transter.

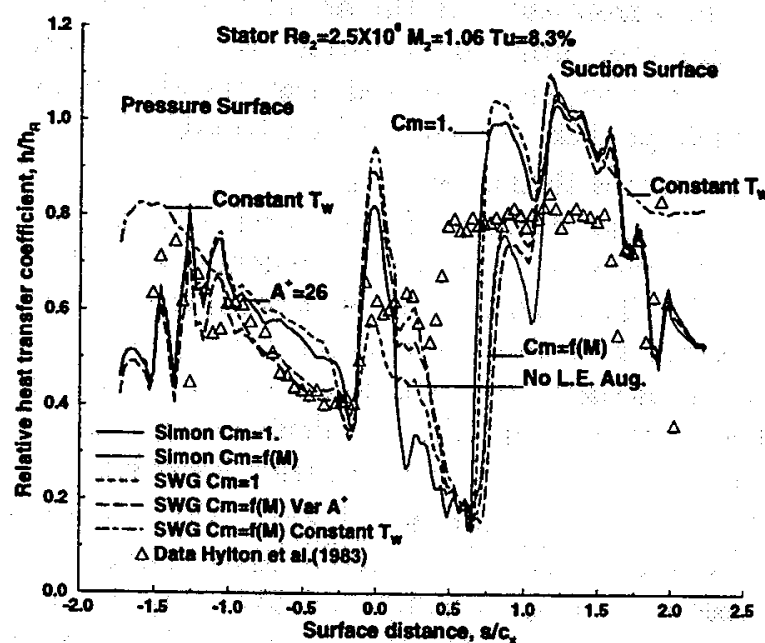

Fig. 10 Effect of model assumptions on predicted heat transfer.

ber correction produced only a small change in the transition behavior. The start of transition was in an adverse pressure gradient region, and the transition length was very short. The results in figure 10 , where transition starts in a favorable pressure gradient region, show a significant effect when the Mach number correction is applied. The suction surface data show an earlier than predicted transition start. However, changing the turbulence intensity at the start of transition from $1 \%$ to $2 \%$ did not improve the agreement with the data. The predicted heat transfer in the leading edge region is higher than the experimental values. Along the pressure surface incorporating $A^{+}$as a function of pressure gradient improved the agreement with the data. Using measured surface temperatures instead of a uniform average temperature resulted in significantly better agreement with the data. However, only the rearward part
Table Il Rotor cases examined

\begin{tabular}{|c|c|c|c|c|c|c|c|c|c|c|}
\hline \multicolumn{11}{|c|}{ Data - Arts et al. (1997) } \\
\hline & & & \multicolumn{4}{|c|}{ Suction } & \multicolumn{4}{|c|}{ Presoure } \\
\hline $\begin{array}{l}\mathrm{Re}_{2} \\
\times 10^{-6} \\
\end{array}$ & $M_{2}$ & $\begin{array}{r}I \\
\%\end{array}$ & $\delta_{S T} / \delta_{T}$ & $\lambda_{0}$ & $899 / 6 T$ & $\overline{\lambda_{99}}$ & ${ }_{S T} / s_{T}$ & $\lambda_{0}$ & $899 / 8 T$ & $\lambda_{99}$ \\
\hline 1.05 & 0.8 & -5.0 & 0.13 & $0 . \overline{031}$ & 0.69 & 0.001 & 0.01 & -0.115 & 0.01 & -0.382 \\
\hline 1.05 & 1.1 & -5.0 & 0.11 & 0.045 & $>1$ & $99 \%$ & 0.01 & -0.261 & 0.01 & -0.183 \\
\hline 1.05 & 1.3 & -5.0 & 0.09 & 0.060 & $>1$ & $97 \%$ & 0.01 & -0.345 & 0.01 & -0.243 \\
\hline 1.84 & 1.1 & -5.0 & 0.07 & 0.196 & 0.54 & -0.034 & 0.01 & -0.268 & 0.01 & -0.187 \\
\hline 1.05 & 1.1 & -14.0 & 0.04 & -0.025 & 0.89 & 0.015 & 0.01 & -0.564 & 0.01 & -0.528 \\
\hline 1.05 & 1.1 & 5.0 & 0.10 & -0.007 & 0.18 & -0.182 & 0.01 & 0.010 & 0.03 & 0.200 \\
\hline
\end{tabular}

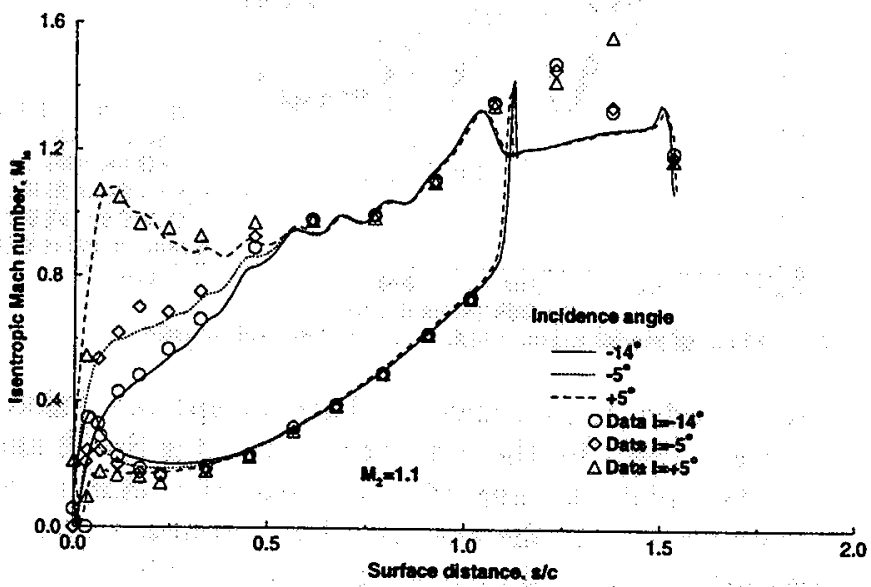

Fig. 11 isentropic Mach number comparisons with data of Arts et al.(1997)

of the vane was affected, and not the region wghere transition occurred.

\section{Rotors}

Only data from a single source are used for comparisons for rotor surface heat transfer. The data used are those of Arts et al. (1997). These data show the variation in surface heat transfer with Reynolds number, Mach number, and perhaps most importantly, rotor incidence angle. All of the comparisons are made at an upstream $T u$ of $4 \%$. Table II shows the same information as presented in Table I, but for the rotor geometry. Figure 11 compares predicted surface isentropic Mach numbers with experimental results at different incidence angles. The primary purpose of this figure is to illustrate the degree to which incidence variations affect the surface pressures. Negative incidence, with the corresponding reduction in flow turning, gives rise to a strongly favorable pressure gradient over much of the suction surface. Away from the leading edge the surface isentropic Mach numbers for the different incidence values converge. The analysis predicts the peak surface Mach number ahead of the experimental data, and the peak predicted value is lower than the data. When the transition region extends to this region the differences in isentropic Mach numbers may affect the agreement between the analysis and experimental heat transfer. 


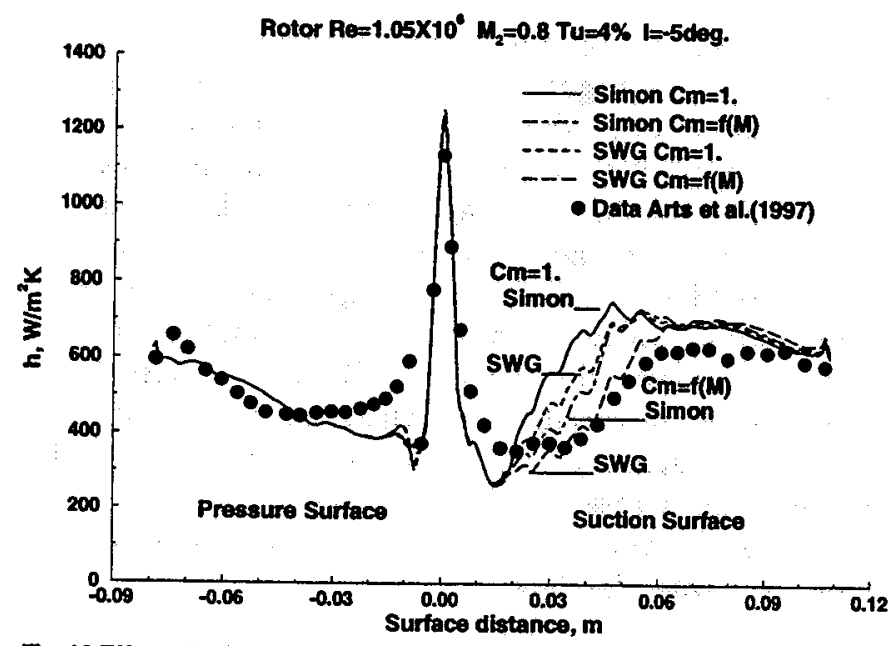

Fig. 12 Effect of Mach number correction on predicted heat transfer.

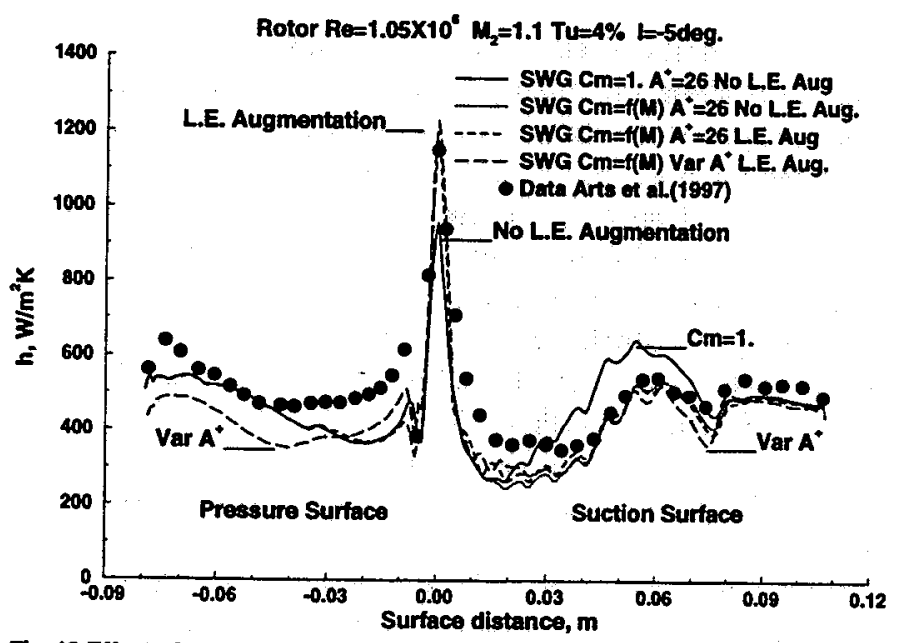

Fig. 13 Effect of model assumptions on predicted heat transfer.

Figures 12, 13, and 14 show the effect of an exit Mach number variation on the length of transition. The agreement between the predicted and experimental isentropic Mach numbers was closer for the subsonic exit Mach number, than for the $M_{2}=1.1$ results shown in figure 11. These results are for an exit Reynolds number of $1.05 \times 10^{6}$. Because the ratio of inlet Mach number to exit Mach number is much greater for a rotor than a stator, there is less variation in the freestream $T u$. Even though $T u=4 \%$ at the inlet, the local $T u$ is greater than $2 \%$ at the start of transition. These results again show that including the effect of Mach number in the transition length modeling improves the agreement with the data. Both model predictions show better agreement with the data when a Mach number correction was used. The SWG model gives the best agreement with the data.

Increasing the exit Mach number to 1.1 did not affect the degree of agreement with the data. A variable near wall damping coefficient, $A^{+}$did not improve the

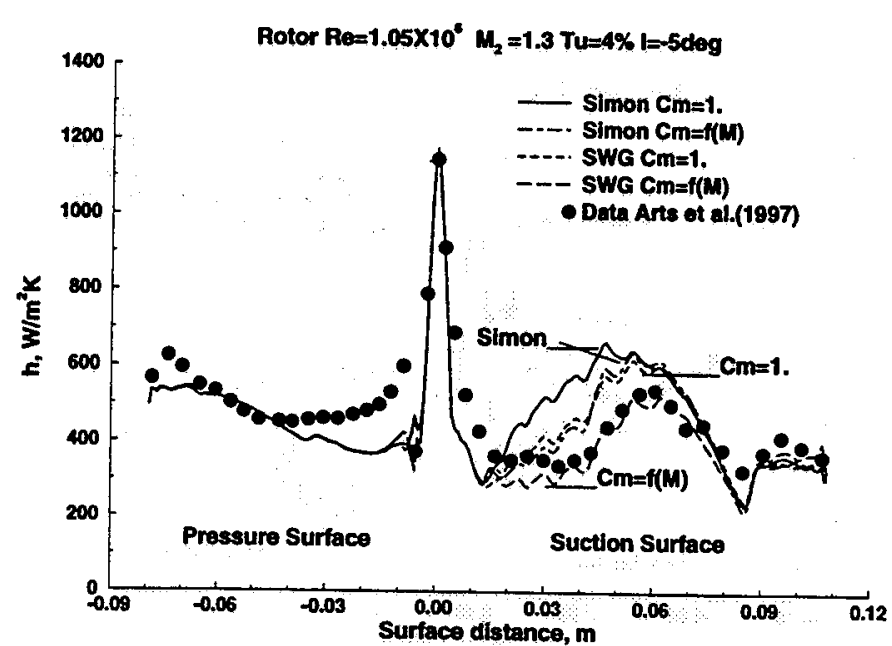

Fig. 14 Effect of Mach number correction on predicted heat transfer.

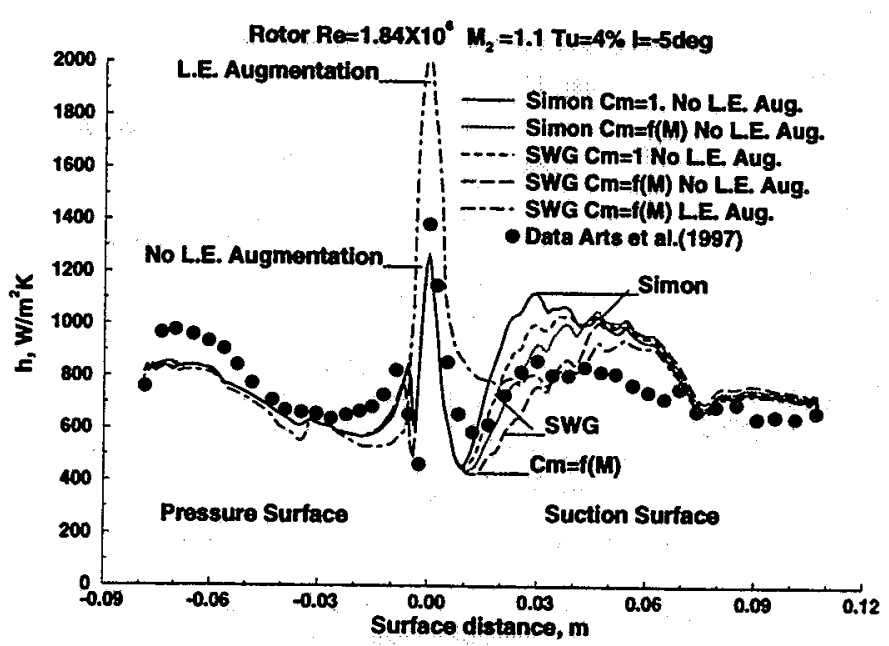

Fig. 15 Effect of model assumptions on prodicted hest transfor.

agreement for the pressure surface heat transfer.

Figure 14 shows evidence of a shock-boundary layer interaction for the highest exit Mach number. The peak isentropic Mach number was calculated to be 1.66. Even in the presence of the shock, the analysis shows good agreement with the experimental data.

Figure 15 shows the effect of an increased exit Reynolds number. Again, including a Mach number correction improved the agreement with the data for the suction surface. At this higher Reynolds number including a leading edge augmentation resulted in heat transfer rates much higher than the experimental data. This behavior is consistent with the arguments advanced by Dullenkopf and Mayle (1992). They concluded that the coefficient in the Smith and Kuethe (1966) leading edge heat transfer model should be decreased as $T u \sqrt{R e_{d}}$ increased. When $T u \sqrt{R e_{d}}>25$, the coefficient in the correlation of Smith and Kuethe (1966) should be reduced to $40 \%$ of its value for low values of $T u \sqrt{R e_{d}}$. The data shown in figure 15 has $T u \sqrt{R e_{d}}=10$. A forty 


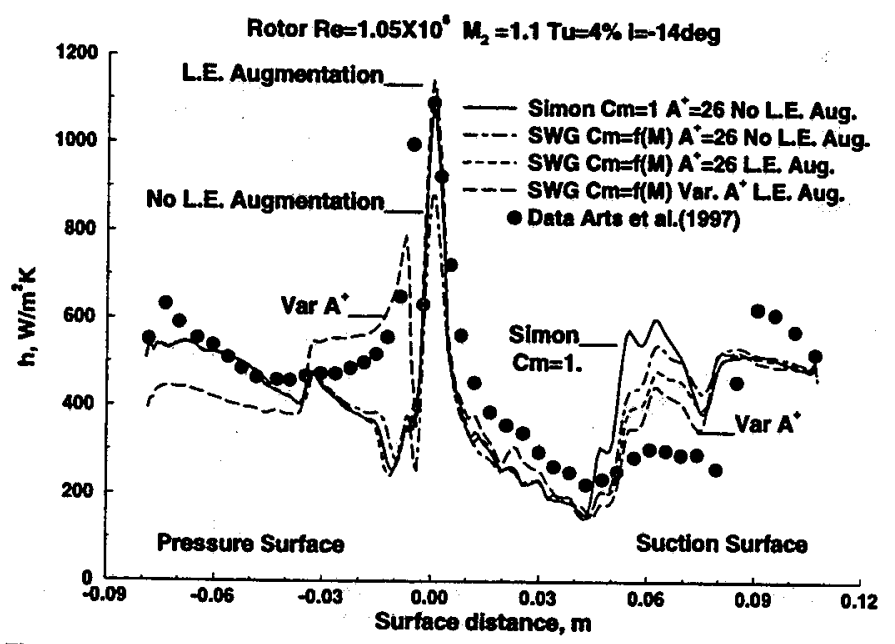

Fig. 16 Effect of model assumptions on predicted heat transter.

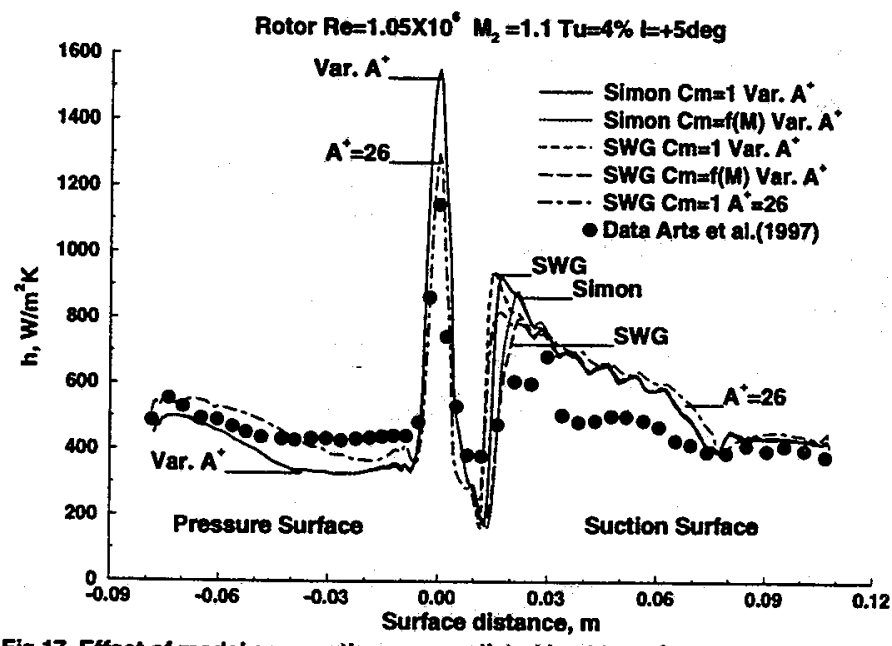

Fig 17. Effect of model assumptions on predicted heat transfor.

to fifty percent reduction in the Smith and Kuethe model coefficient would significantly improve the agreement with the data. The pressure surface comparisons are consistent with those at the lower Reynolds number. A variable $A^{+}$does not improve the agreement with the data.

Comparing figures 13,16 and 17 shows the effect of a variation in pressure gradient caused by a variation in incidence. For a negative incidence of $14^{\circ}$ including a Mach number effect improved the agreement with the data. The higher than measured heat transfer midway on the suction surface implies that $\gamma$ initially increased too rapidly. The positive incidence case shows transition occurring over a very short distance due to the adverse pressure gradient in this region. The positive incidence case is similar to the results shown in figure 9 for the C3X stator data of Hylton et al. (1983), and the degree of agreement is similar.
The prediction of the leading edge heat transfer is good for the two negative incidence cases, but the predicted values exceed the data for the positive incidence case. These results are also consistent with the conclusions of Dullenkopf and Mayle (1992) in that at high Reynolds numbers the correlation of Smith and Kuethe (1966) would overpredict the leading edge heat transfer. For the same exit Reynolds number, the inlet Reynolds number increases with incidence. On the pressure surface the effect of varying $A^{+}$with pressure gradient improved the agreement with data only for the forward region at 14 degrees negative incidence. On the rear portion of the blade, assuming $A^{+}$constant gave good agreement with the data.

\section{CONCLUDING REMARKS}

The results of this work show that a Mach number effect should be incorporated in a transition model. The proposed model accounts for the effect of Mach number on both the frequency of spot formation and the turbulent spot spreading angle. The results shows reasonably good agreement with the experimental data over the length of transition. Almost without exception, including the Mach number effect improved the agreement with the data for both Simon's (1995) model, and for the Solomon, Walker, Gostelow (1995) model.

For moderate to high turbulence levels a simple model for predicting transition onset gives reasonably good agreement with data. When the predicted level of turbulence at the start of transition is below $2 \%$, best agreement with the data was achieved when $R e_{\theta-S T}$ was allowed to increase as the predicted turbulence level decreased to about $1 \%$.

The analysis incorporated a model to account for the effect of freestream turbulence on heat transfer in the laminar and transitioning regions. The model showed reasonably good agreement with the data. However, at high Reynolds numbers the leading edge heat transfer was too high. The approach taken by Dullenkopf and Mayle (1992) might have led to an improved prediction. While the comparisons with data were for the entire blade surface, the primary focus of this investigation was to validate an approach to account for Mach number effects on the length of transition. The appropriateness of using a model to vary the near wall damping coefficient, $\mathrm{A}^{+}$as a function of pressure gradient was not resolved. For the stator cases examined a variable $A^{+}$gave improved agreement. However, for the rotor cases choosing $A^{+}=26$ gave the better agreement. 


\section{REFERENCES}

Ameri, A.A. and Arnone, A., 1992 "Navier-Stokes Heat Transfer Predictions Using Two-Equation Turbulence Closures," AIAA paper 92-3067.

Arnone, A., Liou, M.-S., and Povinelli, L. A., 1992, "Navier- Stokes Solution of Transonic Cascade Flows Using Non-Periodic C-Type Grids," AIAA Journal of Propulsion and Power, Vol. 8, No. 2, pp. 410-417.

Arts, T., Duboue, J.-M., and Rollin, G., 1997, "AeroThermal Performance Measurements and Analysis of a TwoDimensional High Turning Rotor Blade," ASME paper 97GT-120.

Arts, T., Lambert de Rouvroit, M., and Rutherford, A.W., 1990, "Aero-Tremal Investigation of a Highly Loaded Transonic Linear Turbine Guide Vane Cascade," VKI Technical Note 174.

Baldwin, B.S. and Lomax, H., 1978, "Thin-Layer Approximation and Algebraic Model for Separated Turbulent Flows," AIAA Paper AIAA-78-257.

Boyle, R.J., 1991, "Navier-Stokes Analysis of Turbine Blade Heat Transfer," ASME Journal of Turbomachinery, Vol. 113, pp. 392-403.

Boyle, R.J., and Ameri, A..A., 1997, "Grid Orthogonality Effects on Predicted Turbine Midspan Heat Transfer and Performance," ASME Journal of Turbomachinery, Vol. 119, pp. 31-38.

Chen, K.K, and Thyson, N.A., 1971, "Extension of Emmons' Spot Theory to Flows on Blunt Bodies," AIAA Journal of Propulsion and Power, Vol. 9, No. 5, pp. 821-825.

Chima, R.V., 1987 "Explicit Multigrid Algorithm for Quasi-Three- Dimensional Flows in Turbomachinery." AIAA Journal of Propulsion and Power, Vol. 3, No. 5, pp. 397-405.

Chima, R.V., and Yokota, J.W., 1988, "Numerical Analysis of Three-Dimensional Viscous Internal Flows," AIAA paper 88-3522, (NASA TM-100878).

Chima, R.V., Giel, P.W., and Boyle, R.J., 1993, “An Algebraic Turbulence Model for Three-Dimensional Viscous Flows," AAIA paper 93-0083, (NASA TM-105931).

Chima, R.V., 1996, "Application of the $k-\omega$ Turbulence Model to Quasi-Three-Dimensional Turbomachinery Flows," AIAA Journal of Propulsion and Power, Vol. 12, No. 6, pp. 1176-1179.

Clark, J.P., 1993 "A Study of Turbulent Spot Propagation in Turbine Representative Flows," $\mathrm{PhD}$ Thesis St. Catherine's College, University of Oxford.

Clark, J.P., Jones, T.V., and LaGraff, J.E., 1994, “On the Propagation of Naturally Occurring Turbulent Spots," Journal of Engineering Mathematics Vol. 28, pp. 1-19.

Crawford, M.E. and Kays, W.M., 1976, "STAN5 - A Program for Numerical Computation of Two-Dimensional Internal and External Boundary Layer Flows,", NASA CR2742.

Dey, J., and Narasimha, R., 1985 "Spot Formation Rates in High Speed Flows," Report 85 FM 11, Dept. Aero. Eng., Indian Inst. Sci.
Dullenkopf; K. and Mayle, R.E.,1992 "The Effects of Incident Turbulence and Moving Wakes on Laminar Heat Transfer in Gas Turbines;" ASME paper 92-GT-377.

Emmons, H.W., 1951, "The Laminar-Turbulent Transition in a Boundary Layer - Part I," Journal of Aerospace Sciences, Vol. 18, No. 7, pp. 490-498.

Fraser, C.J., Higazy, M.G., and Milne, J.S., 1994, "EndStage Boundary Layer Transition Models for Engineering Calculations," Proceedings of the Institution of Mechanical Engineers, Part $C$, Vol. 208, pp. 47-58.

Gostelow, J.P., Bluden, A.R., Walker, G.J., 1994, “Effects of Free-Stream Turbulence and Adverse Pressure Gradients on Boundary Layer Transition," ASME Journal of Turbomachinery, Vol. 116, pp. 392-404.

Gostelow, J.P., Melwani, N., Walker, G.J., 1995, “Effects of a Streamwise Pressure Gradient on Turbulent Spot Development," ASME paper 95-GT-303.

Hylton, L.D., Mihelc, M.S., Turner, E.R., Nealy, D.A., and York, R.F., 1983, "Analytical and Experimental Evaluation of the Heat Transfer Distribution Over the Surfaces of Turbine Vanes," NASA CR-168015.

Kays, W.M. and Crawford, M.E., 1980, "Convective Heat and Mass Transfer," Second Edition, McGraw-Hill, New York

Mack, L.M., 1969, "Boundary Layer Stability Theory," Document 900-277, Rev A, Jet Propulsion Laboratory, Pasedena, CA.

Mayle, R.E., 1991, “The Role of Laminar-Turbulent Transition in Gas Turbine Engines," ASME Journal of Turbomachinery, Vol. 113, pp. 509-537.

McCormick, M.E., 1968, "An Analysis of the Formation of Turbulent Patches in the Transition Boundary Layer," ASME Journal of Applied Mechanics, Vol. 35, pp. 216-219.

Narasimha, R., 1957, "On the Distribution of Intermittency in the Transition Region of a Boundary Layer," Journal of Aerospace Sciences, Vol. 24, No. 9, pp. 711-712.

Narasimha, R., 1985, "The Laminar-Turbulent Transition Zone in the Boundary Layer," Journal of Aerospace Sciences, Vol. 22, pp. 29-80.

Owen, F.K., and Horstman, C.C, 1972, "Hypersonic Transitional Boundary Layers," AIAA Journal, Vol. 8 pp. 769-775.

Simon, F.F, 1995, "The Use of Transition Region Characteristics to Improve the Numerical Simulation of Heat Transfer in Bypass Transitional Flows," "International Journal of Rotating Machinery, Vol 2, No. 2 pp. 93-102. Also NASA TM 106445.

Simon, F.F, and Ashpis, D.E., 1996, "Progress in Modeling of Laminar to Turbulent Transition on Turbine Vanes and Blades," Presented at the Int. Conf. on Turbulent Heat Transfer, March 10-15 San Diego, CA. Also NASA TM 107180.

Solomon, W.J., Walker, G.J., and Gostelow, J.P., 1995 "Transition Length Prediction For Flows With Rapidly Changing Pressure Gradients", ASME paper 95-GT-241 
Sorenson, R.L., 1980, "A Computer Program to Generate Two-Dimensional Grids About Airfoils and Other Shapes by the Use of Poisson's Equation," NASA TM 81198.

Walker, G.J., 1989, "Transitional Flow on Axial Turbomachine Blading," AIAA Journal Vol. 27, No. 5, pp. 595-602. 
Public reporting burden for this collection of information is estimated to average 1 hour per response, including the time for reviewing instructions, searching existing data sources, gathering and maintaining the data needed, and completing and reviewing the collection of information. Send comments regarding this burden estimate or any other aspect of this collection of information, including suggestions for reducing this burden, to Washington Headquarters Services, Directorate for information Operations and Reports, 1215 Jefferson Davis Highway, Suite 1204, Arlington, VA 22202-4302, and to the Office of Management and Budget, Paperwork Reduction Project (0704-0188), Washington, DC 20503.

\begin{tabular}{|l|l|l}
\hline 1. AGENCY USE ONLY (Leave blank) & $\begin{array}{c}\text { 2. REPORT DATE } \\
\text { June } 1998\end{array}$ & $\begin{array}{r}\text { 3. REPORT TYPE AND DATES COVERED } \\
\text { Technical Memorandum }\end{array}$
\end{tabular}

\section{TITLE AND SUBTITLE}

\section{FUNDING NUMBERS}

WU-523-26-13-00

6. AUTHOR(S)

R.J. Boyle and F.F. Simon

\section{PERFORMING ORGANIZATION NAME(S) AND ADDRESS(ES)}

National Aeronautics and Space Administration

Lewis Research Center

Cleveland, Ohio 44135-3191
8. PERFORMING ORGANIZATION REPORT NUMBER

E-11237
9. SPONSORING/MONITORING AGENCY NAME(S) AND ADDRESS(ES)

National Aeronautics and Space Administration

Washington, DC 20546-0001
10. SPONSORING/MONITORING AGENCY REPORT NUMBER

NASA TM-1998-208404

\section{SUPPLEMENTARY NOTES}

R.J. Boyle, NASA Lewis Research Center and F.F. Simon (formerly NASA Lewis Research Center, presently retired). Responsible person, R.J. Boyle, organization code 5820, (216) 433-5889.

12a. DISTRIBUTIONAVAILABILITY STATEMENT

12b. DISTRIBUTION CODE

Unclassified - Unlimited

Subject Category: 34

Distribution: Nonstandard

This publication is available from the NASA Center for AeroSpace Information, (301) 621-0390.

13. ABSTAACT (Maximum 200 words)

The effect of a Mach number correction on a model for predicting the length of transition was investigated. The transition length decreases as the turbulent spot production rate increases. Much of the data for predicting the spot production rate comes from low speed flow experiments. Recent data and analysis showed that the spot production rate is affected by Mach number. The degree of agreement between analysis and data for turbine blade heat transfer without film cooling is strongly dependent of accurately predicting the length of transition. Consequently, turbine blade heat transfer data sets were used to validate a transition length turbulence model. A method for modifying models for the length of transition to account for Mach number effects is presented. The modification was made to two transition length models. The modified models were incorporated into the two-dimensional Navier-Stokes code, RVCQ3D. Comparisons were made between predicted and measured midspan surface heat transfer for stator and rotor turbine blades. The results showed that accounting for Mach number effects significantly improved the agreement with the experimental data.

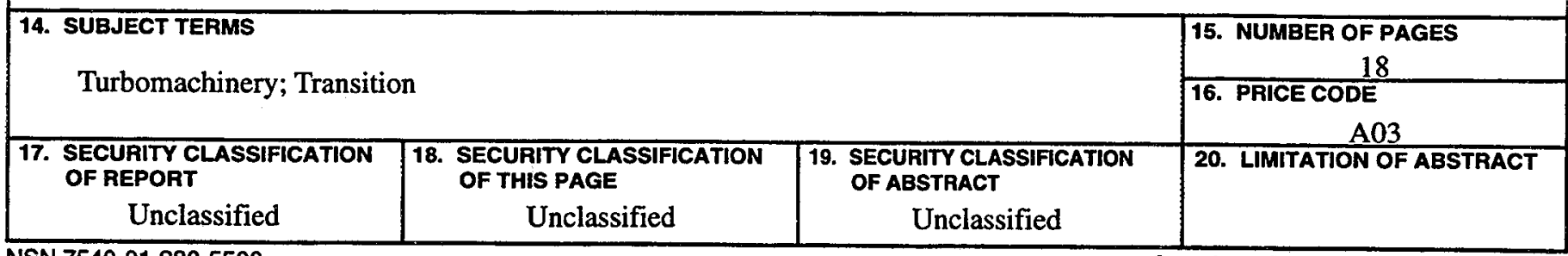

